\title{
APPLICATION OF INTERLINE POWER FLOW CONTROLLER (IPFC) FOR POWER TRANSMISSION SYSTEM
}

\author{
Y.N.Vijayakumar ${ }^{1}$, Dr. Sivanagaraju ${ }^{2}$ \\ Department of EEE, SVCET, Chittoor, A.P, India ${ }^{1}$ \\ Department of EEE, JNTUK, Kakinada, A.P, India $^{2}$
}

\begin{abstract}
The interline power flow controller (IPFC) is one of the latest generation flexible AC transmission systems (FACTS) controller used to control power flows of multiple transmission lines. In recent years, power demand has increased substantially while the expansion of power generation and transmission. It has been severely limited due to limited resources and environmental limitations. Flexible AC Transmission Systems (FACTS) controllers have been mainly used for solving various power system steady state control problems. Interline Power Flow Controller is a versatile device can be used to control power flows of a multi-line system or sub-networks An Interline Power Flow Controller (IPFC) is a converter based FACTS controller for series compensation with capability of controlling power flow among multi-lines within the same corridor of the transmission line. It consists of two or more Voltage Source Converters (VSCs) with a common dc-link. Real power can be transferred via the common dc-link between the VSCs and each VSC is capable of exchanging reactive power with its own transmission system. In this paper, a control scheme of an IPFC system with two VSCs to compensate the impedances of two similarly dimensioned parallel transmission lines is presented. A Mathematical model of the IPFC is presented and the model is used to investigate the flexibility of power flow control, in the presence of operating constraints of the IPFC. In this paper, the application of Interline Power Flow Controller (IPFC) in damping of low frequency oscillations is investigated. The potential of various IPFC control signals upon the power system oscillation stability is investigated under various loading conditions.
\end{abstract}

Key words: FACTS, IPFC, VSC, SSSC, Series Compensation, Voltage Stability, VSI, PSO, MATLAB/SIMULINK

\section{I.INTRODUCTION}

The most powerful and versatile FACTS devices are unified power flow controller (UPFC) and interline power flow controller (IPFC). It is found that, in the past, much effort has been made in the modeling of the UPFC for power flow analysis. However, UPFC aims to compensate a single transmission line, whereas the IPFC is conceived for the compensation and power flow management of multi-line transmission system. Interline power flow controller (IPFC) is a new member of FACTS controllers. Like the STATCOM, SSSC and UPFC, the IPFC also employs the voltage sourced converter as a basic building block. A simple model of IPFC with optimal power flow control method to solve overload problem and the power flow balance for the minimum cost has been proposed. A multi-control functional model of static synchronous series compensator (SSSC) used for steady state control of power system parameters with current and voltage operating constraints has been presented. The injection model for congestion management and total active power loss minimization in electric power system has been developed. The Unified Power Flow Controller (UPFC) proposed by Gyugyi is the most versatile FACTS controller for the regulation of voltage and power flow in a transmission line. It consists of two voltage source converters (VSC) one shunt connected and the other series connected. The DC capacitors of the two converters are connected in parallel shown in figure 1 . If the switches 1 and 2 are open, the two converters work as STATCOM and SSSC controlling the reactive current and reactive voltage injected in shunt and series respectively in the line. The closing of the switches 1 and 2 enable the two converters to exchange real (active) power flow between the two converters. The active power can be either absorbed or

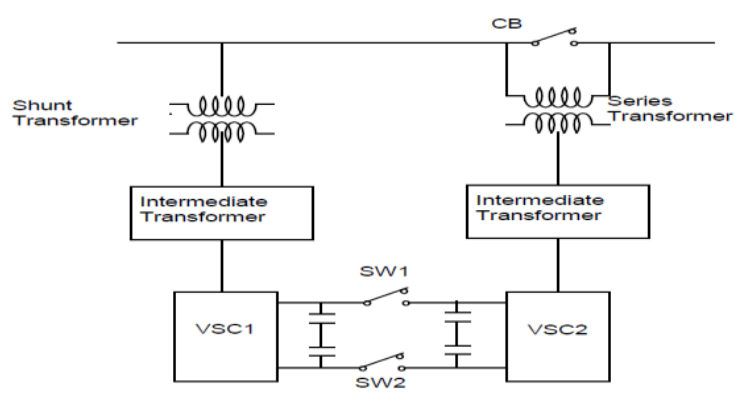

Fig.1. UPFC Schematic.

supplied by the series connected converter. The Interline Power Flow Controller (IPFC) concept proposed in this paper addresses the problem of compensating a number of transmission lines at a given substation. Conventionally, series capacitive compensation (fixed, thyristor-controlled or SSSC based) is employed to increase the transmittable real power over a given line and also to balance the loading of a normally encountered multi-line transmission system. However, independent of their implementation, series reactive compensators are unable to control the reactive power flow in, and thus the proper load balancing of, the lines. This problem becomes particularly evident in those cases where the ratio of reactive to resistive line impedance $(\mathrm{Xm})$ is relatively low. Series reactive compensation reduces only the effective reactive impedance $X$ and, thus, significantly decreases the effective $X / R$ ratio and thereby increases the reactive power flow and losses in the line. The IPFC scheme proposed provides, together with 
independently controllable reactive series compensation of each individual line, a capability to directly transfer real power between the compensated lines. This capability makes it possible to: equalize both real and reactive power flow between the lines; transfer power demand from overloaded to under loaded lines; compensate against resistive line voltage drops and the corresponding reactive power demand; increase the effectiveness of the overall compensating system for dynamic disturbances. In other words, the IPFC can potentially provide a highly effective scheme for power transmission management at a multi-line substation as shown in figure 2 .

A pure series reactive (controllable) compensation in the form of TCSC or SSSC can be used to control or regulate the active power flow in the line, the control of reactive power is not feasible unless active (real) voltage in phase with the line current is not injected. The application of a TCSC (or SSSC with impedance emulation) results in the reduction of net series reactance of the line. However, $\mathrm{X} / \mathrm{R}$ ratio is reduced significantly and thereby increases the reactive power flow (injected at the receiving end) and losses in the line. The interline power flow controller (IPFC) provides, in addition to the facility for independently controllable reactive (series) compensation of each individual line, a capability to directly transfer or exchange real power between the compensated lines. This is achieved by coupling the series connected VSC in individual lines on the DC side, by connecting all the DC capacitors of individual converters in parallel. Since all the series converters are located inside the substation in close proximity, this is feasible.

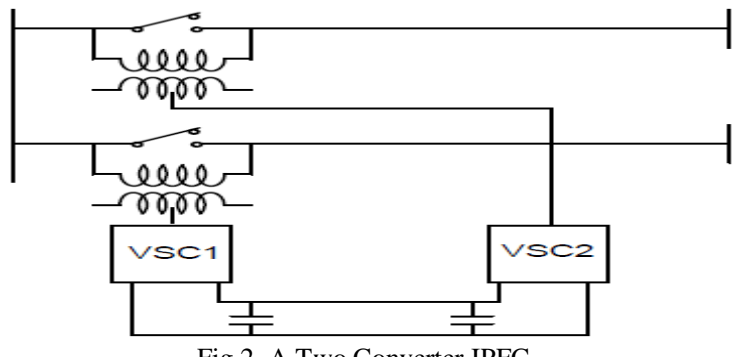

Fig.2. A Two Converter IPFC

The concept of combining two or more converters can be extended to provide flexibility and additional degrees of freedom. A generalized UPFC refers to three or more converters out of which one is shunt connected while the remaining converters are series connected as shown in figure 3.

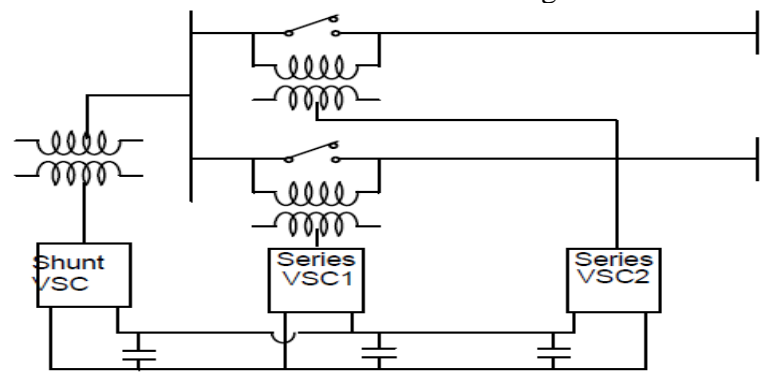

Fig.3. A Three Converter GUPFC

\section{POWER FLOW CONTROLLING DEVICES}

Power flow is controlled by adjusting the parameters of a system, such as voltage magnitude, line impedance and transmission angle. The device that attempts to vary system parameters to control the power flow can be described as a Power Flow Controlling Device (PFCD).

Depending on how devices are connected in systems, PFCDs can be divided into shunt devices, series devices, and combined devices (both in shunt and series with the system), as shown in Figure 4.

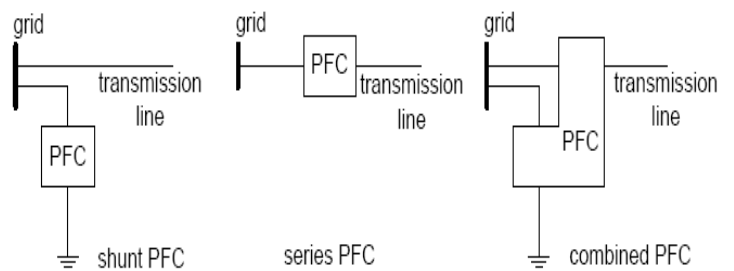

Fig.4 Simplified diagram of shunt, series and combined devices

A shunt device is a device that connects between the grid and the ground. Shunt devices generate or absorb reactive power at the point of connection thereby controlling the voltage magnitude. Because the bus voltage magnitude can only be varied within certain limits, controlling the power flow in this way is limited and shunt devices mainly serve other purposes.

For example, the voltage support provided by a shunt device at the midpoint of a long transmission line can boost the power transmission capacity.

A combined device is a two-port device that is connected to the grid, both as a shunt and in a series, to enable active power exchange between the shunt and series parts. Combined devices are suitable for power flow control because they can simultaneously vary multiple system parameters, such as the transmission angle, the bus voltage magnitude and the line impedance.

Normally, the High Voltage DC transmission (HVDC) and PE devices that are applied at the distribution network, such as a Dynamic Voltage Restorer (DVR), are also considered as FACTS controllers. Most of the FACTS controllers can be used for power flow control. However, the HVDC and the DVR are out of the scope of the PFCD. The relationship between the PFCDs, FACTS controllers and mechanical controller is shown in Figure 5.

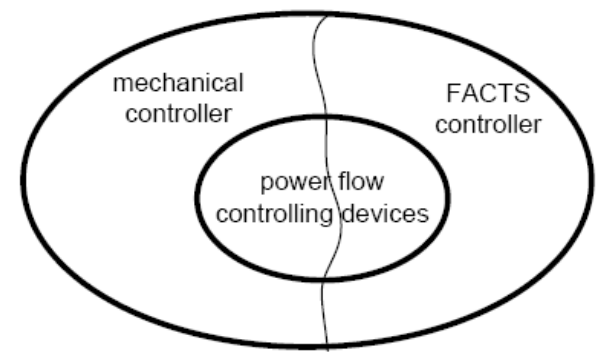

Fig.5. Relationship between the PFCDs, FACTS controllers and mechanical Controller

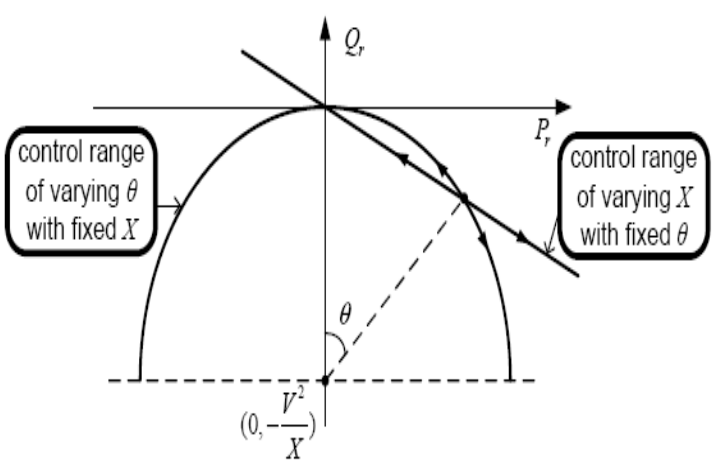

Fig.6. Control range of active and reactive power flows with vary $\theta$ and $\mathrm{X}$ 


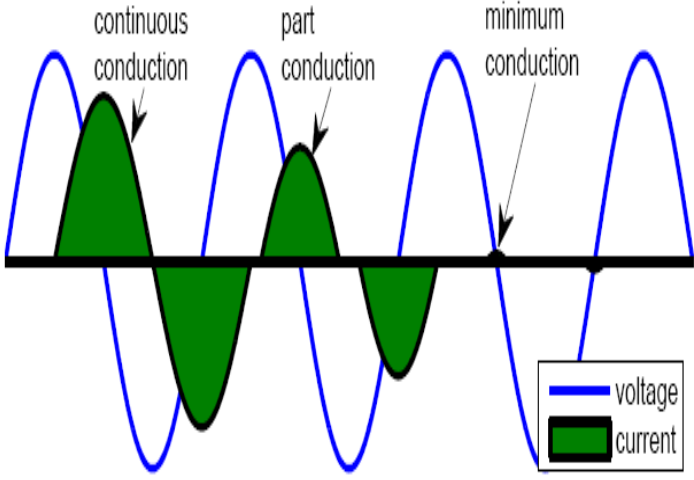

Fig.7. Voltage and current waveforms of a TCR for different firing angles

TCR employs the firing angle control to the Thyristors to vary the current thereby controlling the shunt reactance of the TCR. The firing angle varies from a 90。 delay, for continuous conduction to $180^{\circ}$ delay, for minimum conduction, as shown in Figure 6-7. A TCR combined with TSCs is able to provide continuously variable VAR injection or absorption.

\section{STATCOM}

A static synchronous compensator (STATCOM) is basically a VSC that is connected between a grid and the ground through a coupling inductance, as shown in Fig.8. The STATCOM acts as an AC voltage source and has characteristics similar to a synchronous condenser (a synchronous generator that is running idle and used for reactive compensation). The STATCOM injects an AC current in Quadrature (leading or lagging) with the grid voltage, and emulates capacitive or inductive impedance at the point of connection.

If the voltage generated by the STATCOM is less than the grid voltage, it will act as an inductive load and withdraw reactive powers from the system. Conversely, when the STATCOM voltage is higher than the grid voltage, it will act as a capacitor load and provide reactive power to the grid. Compared to the synchronous condenser, the STATCOM is a PE-based device without inertia and therefore has a faster dynamic response.

It consists of a three-phase current-fed converter, whose outputs are connected to a three-phase full-bridge diode rectifier through a delta-delta wound three-phase transformer.

The three-phase current-fed converter is divided into a threephase full-bridge converter configured as six main MOSFET switches $(S 1-S 6)$ for three-phase dc/ac conversion, one auxiliary MOSFET switch $(S c)$ and clamp capacitor $C c$ for the active clamp and a dc boost inductor $L_{\mathrm{dc}}$ acting as a current source.

The DC VSC is the most common type of converter that used for the STATCOM and the DC voltage source can be a capacitor. By using a multi-level, multi-phase, or Pulse-Width Modulated (PWM) converter, the current distortion of the STATCOM outputs can be sufficiently reduced and the STATCOM may even require no filtering.

Fig. 9 shows the waveforms of a voltage generated by a five-level STATCOM and the corresponding current.

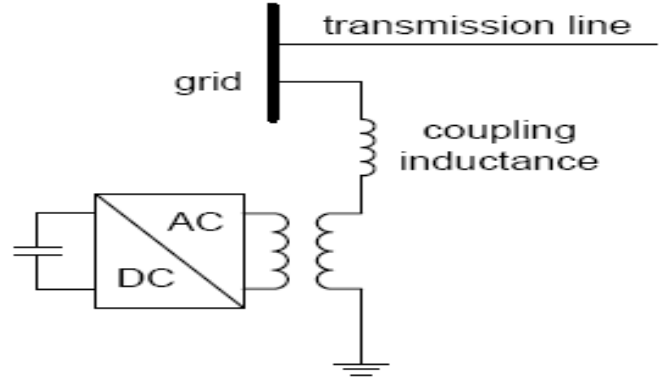

Fig.8. STATCOM configuration

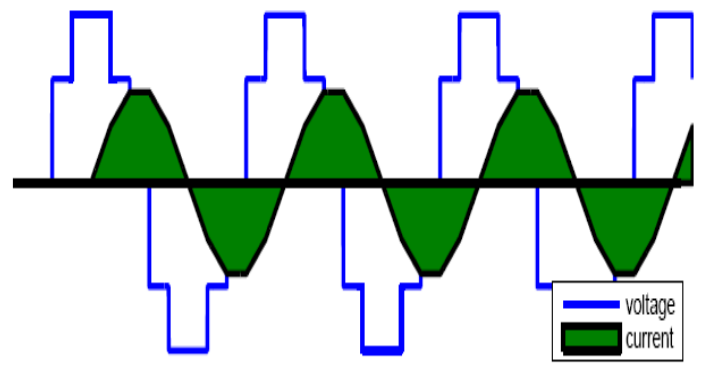

Fig.9 Voltage and current waveforms generated by a five-level STATCOM

\section{INTERLINE POWER FLOW CONTROLLER (IPFC)}

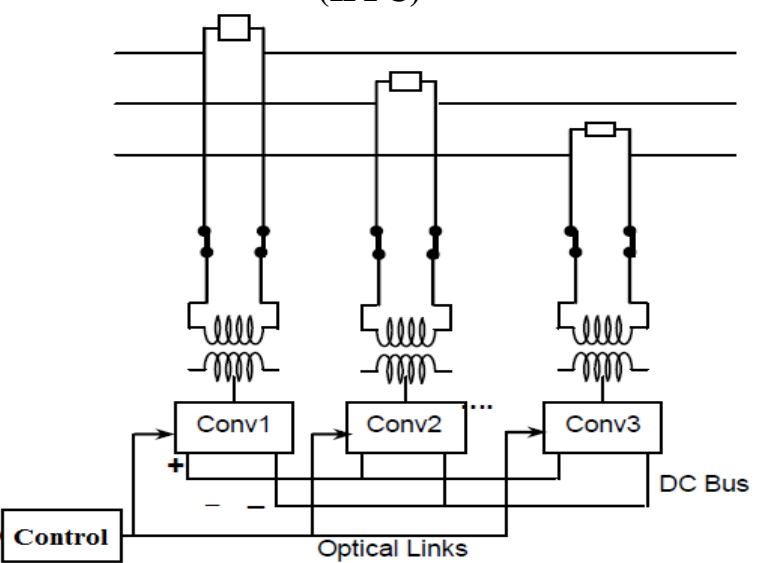

Fig.10 IPFC Comprising n Converters

Figure 10 shows the Interline Power Flow Controller (IPFC) provides, in addition to the facility for independently controllable reactive (series) compensation of each individual line, a capability to directly transfer or exchange real power between the compensated lines.

This is achieved by coupling the series connected VSCs in individual lines on the DC side, by connecting all the DC capacitors of individual converters in parallel. Since all the series converters are located inside the substation in close proximity, this is feasible.

For the system shown in Fig. 11 we can express the received power and the injected reactive power at the receiving end of the prime line by the following expressions. 


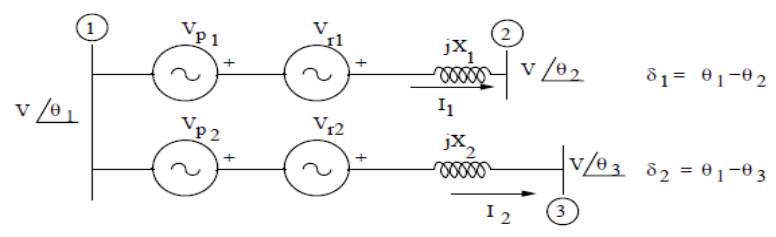

Fig.11 Representation of IPFC

$$
\begin{aligned}
& P_{1}=P_{10}+\frac{V V_{p 1}}{X_{1}} \sin \left(\frac{\delta_{1}}{2}-\phi_{1}\right)+\frac{V V_{r 1}}{X_{1}} \cos \left(\frac{\delta_{2}}{2}-\phi_{1}\right) \\
& Q_{1}=Q_{10}+\frac{V V_{p 1}}{X_{1}} \cos \left(\frac{\delta_{1}}{2}-\phi_{1}\right)+\frac{V V_{r 1}}{X_{1}} \sin \left(\frac{\delta_{2}}{2}-\phi_{1}\right)
\end{aligned}
$$

Fig. 12 shows the scheme of an IPFC having two VSCs. In this scheme, a master control system is used to compensate both resistive and inductive impedances of the Line 1 power system, and the slave control system is used to regulate the reactance of Line 2 and maintain the common dc-link voltage.

Fig. 13 shows the control diagram of the slave IPFC system. It consists of three control loops: (a) for regulating the injected reactance, (b) for regulating the dc-link voltage, and (c) for balancing the voltages on the dc side capacitors.

Fig. 14 shows the overall control structure of the master IPFC system. This block diagram is similar to the block diagram of the slave IPFC system, and has many of the same blocks except for two major differences:

(a) the dc voltage controller and (b) the controller are no longer needed. However, here two control loops are required to regulate the d- and q-components in the synchronous reference frame in order to regulate both the reactance and resistance of the Line 1 .

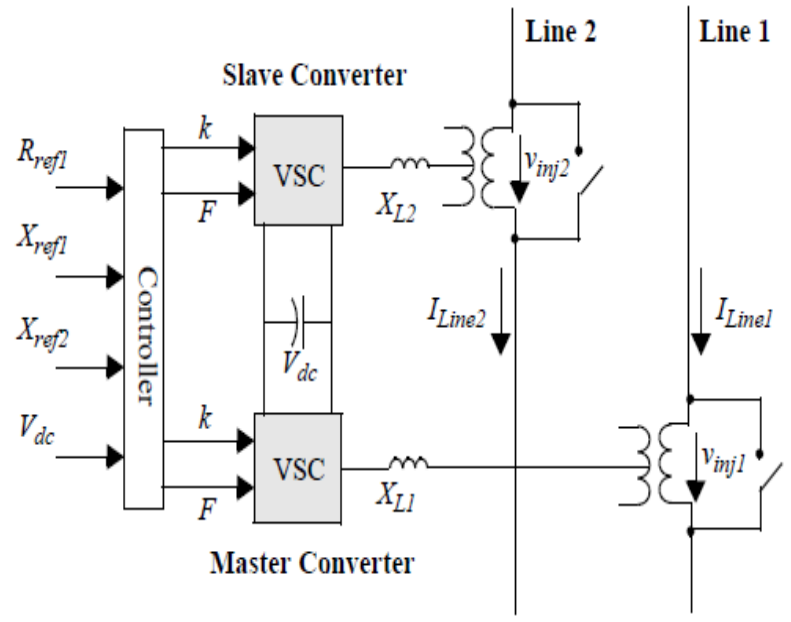

Fig.12 Schematic of an IPFC

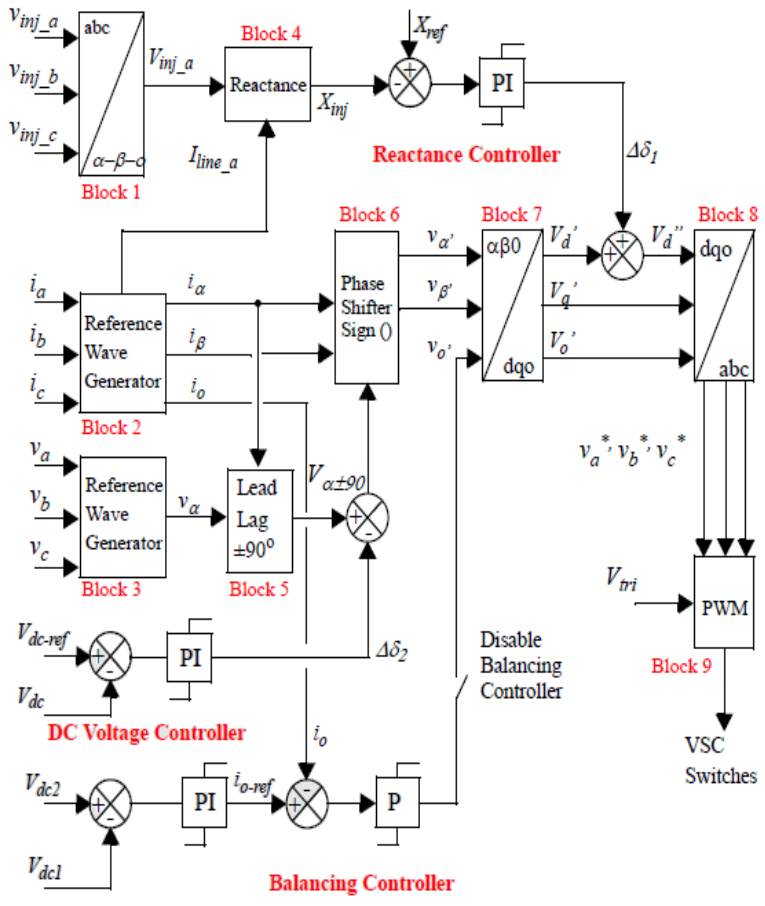

Fig.13 IPFC Slave Converter System Controller

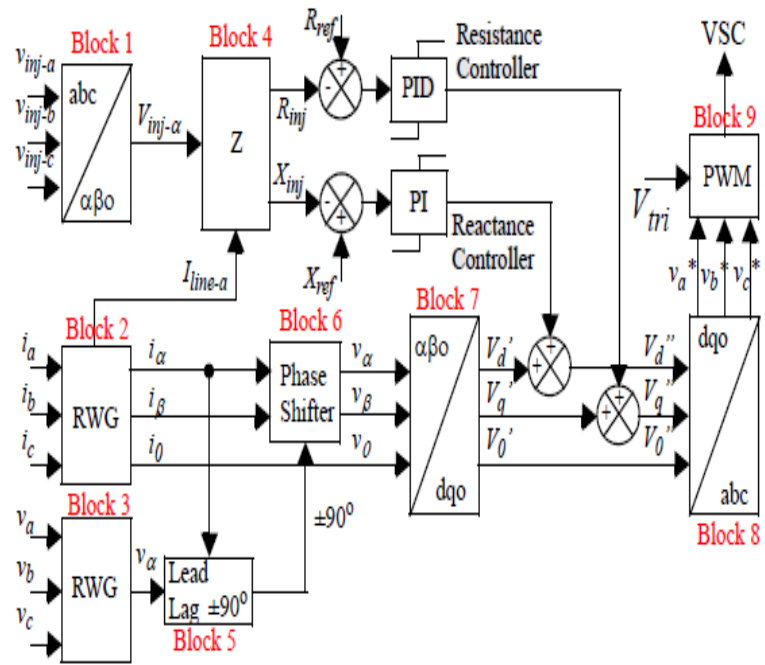

Fig.14 IPFC Master Converter System Controller 


\section{Control of Active Power}
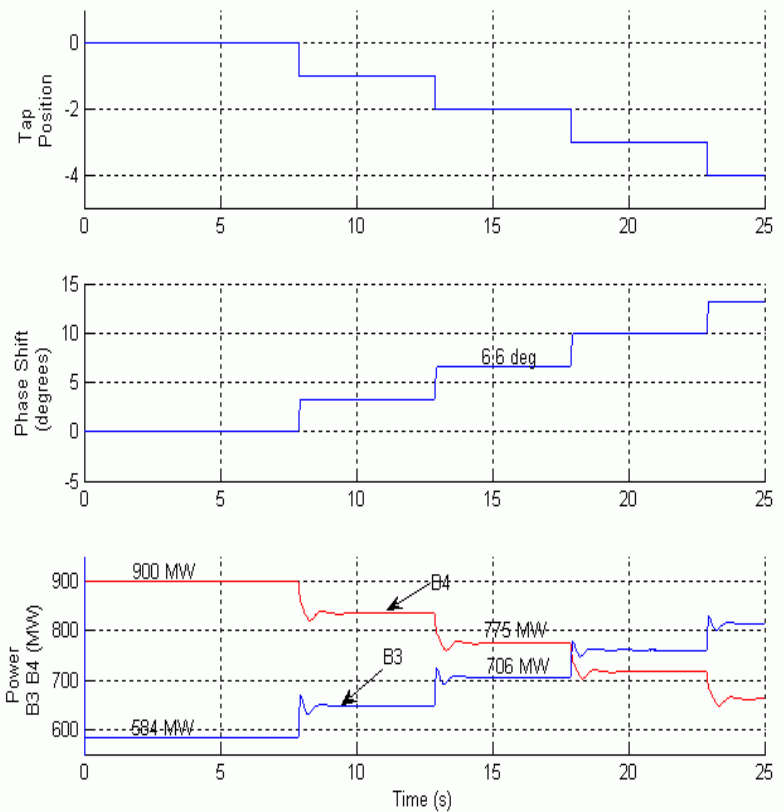

Fig.15 IPFC Active Power Flow Control

\section{Dynamic Response to a Change in Reference Power}
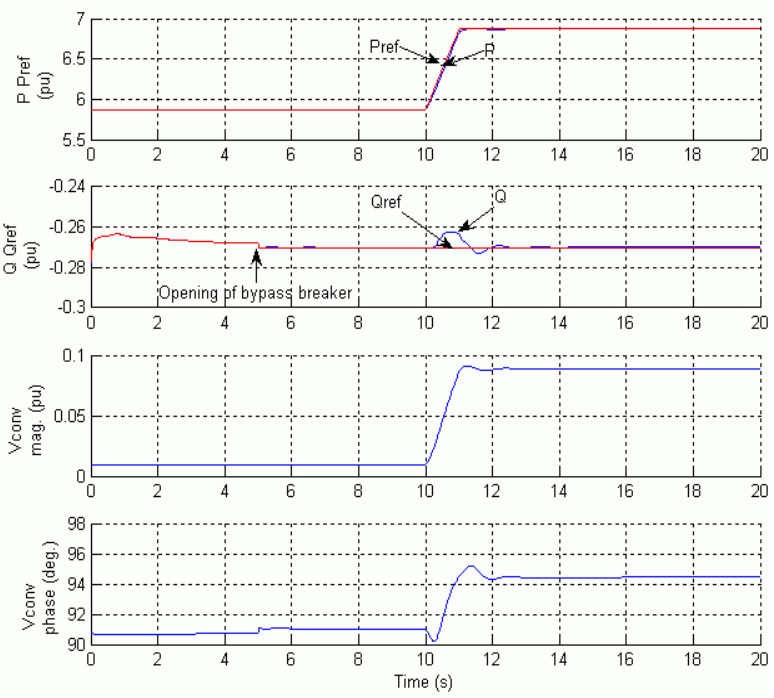

Fig.16 IPFC Dynamic Response

\section{CONCLUSION}

The study of an IPFC system with two parallel lines has demonstrated the flexible control of active/reactive power to assist in the transmission system. The behavior of the system under various transient and load changes at the receiving-end of the transmission system are presented and analyzed. A balancing circuit based on zero sequence current is employed to equalize the dc link capacitor voltages. A mathematical model of the IPFC in steady state has been developed in this paper. The model was used to investigate the operating limits based on the controllability of power flow in the transmission line due to the initial loading levels in the network. It has been shown that the range of power flow control could be maximized using special control strategies. IPFC like other FACTS Controller contribute to the optimal system operation by reducing the power loss and improving the voltage profile. The IPFC is a kind of combined compensators, which combines at least two SSSCs via a common DC voltage link. This DC voltage link provides the device with an active power transfer path among the converters, which enables the IPFC to compensate multiple transmission lines at a given substation. This is a very attractive feature of this FACTS device. The effectiveness of the IPFC based damping controller has been investigated in damping low frequency oscillations. Dynamic simulations results have emphasized that the damping controller which modulates the control signal provides satisfactory dynamic performance under wide variations in loading condition and system parameters.

\section{REFERENCES}

1. [1] Y. Xiao, Y. H. Song, and Y. Z. Sun, "Power flow control approach to power systems with embedded FACTS devices," IEEE Trans. Power Syst., vol. 17, no. 4, pp. 943-950, Nov. 2002

2. [2] L. Gyugyi, K. K. Sen, and C. D. Schauder, "The interline power flow controller concept a new approach to power flow management in International Journal of Electrical and Electronics Engineering 4:7 2010495 transmission systems," IEEE Trans. Power Del., vol. 14, no. 3, pp. 1115-1123, Jul. 1999.

3. [3] S. Teerathana, A. Yokoyama, Y. Nakachi, and M.Yasumatsu, "An optimal power flow control method of power system by interline power flow controller (IPFC)," in Proc. 7th Int. Power Engineering Conf, Singapore, pp. 1-6, 2005.

4. [4] X.P. Zhang, "Advanced modeling of the multicontrol functional static synchronous series compensator (SSSC) in Newton power flow," IEEE Trans. Power Syst., vol.18, no. 4, pp.1410-1416, Nov.2003.

5. [5] Y. Zhang, Y. Zhang and C. Chen, "A novel power injection model of IPFC for power flow analysis inclusive of practical constrains ", IEEE Transactions on Power Sys tems, Vol. 21, No. 4, November 2006

6. [6] Zhou, E.Z. (1993) 'Application of Static VAR Compensators to Increase Power System Damping', IEEE Trans. PWRS., pp. 655-661.

7. [7] Hammad, A.E. (1986) 'Analysis of Power System Stability Enhancement by Static VAR Compensators', IEEE Trans., pp. 222-227.

8. [8] Laszlo Gyugyi, Kalyan K. Sen, Colin D. Schauder, “ The Interline Power Flow Controller Concept : A New Approach to the Power Flow Management," IEEE Trans. on Power Delivery, Vol.14, no. 3, pp 1115 - 1123, July 1999.

9. [9] A. P.Usha Rani and B. S.Rama Reddy, "Modeling and Digital Simulation of Interline Power Flow Controller System" International Journal of Computer and Electrical Engineering, Vol. 2, No. 3, June, 2010, pp. 1793-8163. 